\title{
Anti-Oxidant Property of Eichhornia Crassipes In Oil Samples
}

\author{
Opia, Anthony Chukwunonso, Abdul Hamid, Mohd Kameil Bin, Syahrullail Samion
}

\begin{abstract}
This study on Eichhornia Crassipes focus on its advantageous contribution to oil sample protection through its anti-oxidant and anti-corrosion properties. It was discovered to possess antioxidant constituents of phospholipid with strong structure of amphipathic molecules with much of hydrophobic strength. Eichhornia Crassipes contain triglycerides known as lutein, lycopene, $\alpha$-Tocopherol, zeaxanthin, astaxanthin which help in protecting lubricants against oxidation, corrosion, thermolysis and hydrolysis. These good potential helps in neutralizing acids also the chitins potential found at the root region of the plant, serves as destroyer for some dangerous contaminants in the lubricant. This function as a key quid in extending the life span of an oil lubricant degradation from occurring. However, the antioxidants still deplete in the process as a result of vigorous reactions to the formation of some acids in the system.
\end{abstract}

Keywords: Anti-oxidant, degradation, Eichhornia Crassipes, lubricants, and phospholipid.

\section{INTRODUCTION}

Degradation of oil lubricant causes series of catastrophes in the operational performance and overall output of an engine set up. Inability of lubricants to resist redox reaction, corrosion and even rust, completely affect the lubricating performance. These further lead to friction and wear, to form the most dangerous impact on engine elements. All mechanisms in machine set up involve a lot of mechanical contacts between various surfaces [1]. Wear impact shorten machine service life, causes machine malfunction and enormous losses, due to interrupted production. To minimize the impact and misadventure failure caused by oxidation/corrosion effect (friction structures), lubricants with sufficient anti-oxidants are usually introduced. In

Revised Manuscript Received on October 30, 2019.

* Correspondence Author

Opia, Anthony Chukwunonso, Faculty of Mechanical Engineering, dept. of Aeronautics, Automotive and Ocean Engineering. Universiti Tecknologi Malaysia.

Contact:

+2347038272562.(E-mail:anthonyopia17@yahoo.com).

Abdul Hamid, Mohd Kameil Bin, Faculty of Mechanical Engineering, dept. of Aeronautics, Automotive and Ocean Engineering. Universiti Tecknologi Malaysia. E-mail: kameil@mail.fkm.utm.my)

Syahrullail Samion, : Faculty of Mechanical Engineering, Universiti TeknologiMalaysia,81310UTM,Skudai,Johor.Email:syahruls@mail.fkm.ut m.my Web : http://www.fkm.utm.my/ syahruls/. Contact: +607-553-4699

(c) The Authors. Published by Blue Eyes Intelligence Engineering and Sciences Publication (BEIESP). This is an open access article under the CC BY-NC-ND license (http://creativecommons.org/licenses/by-nc-nd/4.0/) machine operation, energy losses are recorded and negatively affects machine efficiency [2].

In support of current sustainability strive_towards innovative change in a balanced environment, whereby the exploitation of resources, the phase of investments, the inclination of technological development and institutional change are compounded as the formula to enhance both current and future potential to meet human needs and aspirations. This challenges have become more critical concern in the field of tribology most especially where oxidation and corrosions are much observed like in maritime industry [3]. Though series of nanoparticles (NPs) have been studied by biomedical and nanotechnology researcher and their demand together with applications in the industrial utilization has been for past decades [4].Notwithstanding, the toxic effect of those inorganic substances as anti-oxidants in oil samples will not be under-estimated. In addition, the resultant destructive effect of nano-toxicology had been discussed by bio-researcher with better understanding and more insights towards bio-materials that is ecological friendly [4]-[7]. Currently, major fuel and lubricants together with its additives (anti-oxidants) used by internal combustion engines are petroleum (synthetic) derived products [8]. The final product of these materials, turns to be a serious challenge to our ecosystem due to the emission of gasses especially the greenhouse gas [9], [10].Adopting the world sustainability strive in order to combat these poisonous emissions, alternative lubricants and additives through green technology are being formulated for existing engines with or without modifications [11]. Bio-additives and lubricants have better affinity to metal surfaces in terms of tribological performance, provides better anticorrosion than petroleum derived type [4], [12], [13]. Eichhornia Crassipes processed compounds with some good potentials are active green substitute to toxic inorganic compound constitutes like Sulphur (S) and Phosphorus (P) based additives. It also has capacity in synergetic enhancement with conventional ZDDP and other high additives [14].According to American Petroleum Institute (API), group 1 base oils in the line of the five groups of base oils are in decline [15][16]-[18] Mineral oil of group 11 and 111 base oils, that are more refined as well as fully synthetic polyalphaolefines (PAO) which represents group IV, can be found in an increasing number of commercial lubricant formulations [19]. Group V summarizes all of the other types of base oils such as silicones, polyalkylene glycol (PAG) ethers, phosphate esters, bio-lubes, and various synthetic esters [8], [18].Oxidation rate as part of oil degradation, depends on quality and base oil type, as well as synergetic of additives package used. Some of well refined synthetics oil like polyalphaolefins (PAO), constitutes better oxidation stability than counterpart of mineral oils [16], [20]. 


\section{Anti-Oxidant Property Of Eichhornia Crassipes In Oil Samples}

This enables the oil to resist oxidation at some higher operating temperatures thus improve oxidation stability. It concisely stated that hydro-treated base stocks class have superior oxidation resistance and thermal stability than does solvent-refined class base oil [21]. Solvent approach of refining, results in base oil production, that contain more of natural anti-oxidants of sulphur compounds. These categories of base oil retain a natural tendency to prevent oxidation, while the class of hydro-treated base oils must be providing with additional anti-oxidants for oxidation stability and thermal balancing. Many of hydro-treated base oils have very poor solubility characteristics [22]. Reason could be improper formulation, resulting in additives suspensions after blending. In the operation, immediately the anti-oxidants are depleted or weakened in defending lubricant, the oxidation of the oil might occur very rapidly [23].

\section{EICHHORNIA CRASSIPES AS A SOURCE OF ANTI-OXIDANTS/CORROSION TO OIL SAMPLES}

Water hyacinth with a botanical name Eichhornia Crassipes Martius, is a weed ubiquitously monocotyledonous plant found in rivers, lakes and other water bodies across the globe. Classified to the family potederiaceae of lily group (liliaceae), and originated from Brazil and Equador region. It bears aesthetically pleasing coloured flowers along their round to oblong curved leaves and waxy coated petioles. The growth is highly proliferation with inches to about a meter in height. To enable it float, its leaves and stem contain air filled sacs. Despite the challenges associated with the proliferation growth by blocking the water ways thereby makes navigation and other water activities difficult. The nature and growths also serves as promoters for bacteria and other water diseases. In the other hand, it further provides advantageous potentials [24]-[26] in traditional medicine, used in phytoremediation, industrial oil applications and also applied in removal of toxic elements from polluted water bodies. Substances capable of resisting corrosion are mostly soluble in base oil [18][27]. With high potential in functional groups of physical binding on the surface of elements by creating an active passive layer of defense [6]. For good performance in protecting engine components against degradation effect by oxidation/corrosion on base oil, the layer has to be closely packed to resist water and oxygen penetration [28]. The actualization of this target comes as a result of strong and dipolar groups and oil dissolve tail known as hydrophobicity tendency with unbranched and long alkyl chain [6][29].Any material (Eichhornia crassipes) that contain substances of surface-active molecules with high potential in amphiphilic, chitin and chitosan compounds is known as surfactants [30][31]. With Water hyacinth properties (hydrophobic tail and little hydrophilic tail), contain a unique structure as a surfactant, were the hydrocarbon tail extended into oil phase without losing its properties (insoluble) in water, hence provides good transition between water and oil phase [31]. A successful report on the use of cotton and silica nanoparticles for sorbent application discovered of same behavior with Eichhornia crassipes. [20]. The important constituents in Eichhornia crassipes that proves it suitable for the application are illustrated in figure 1 below.

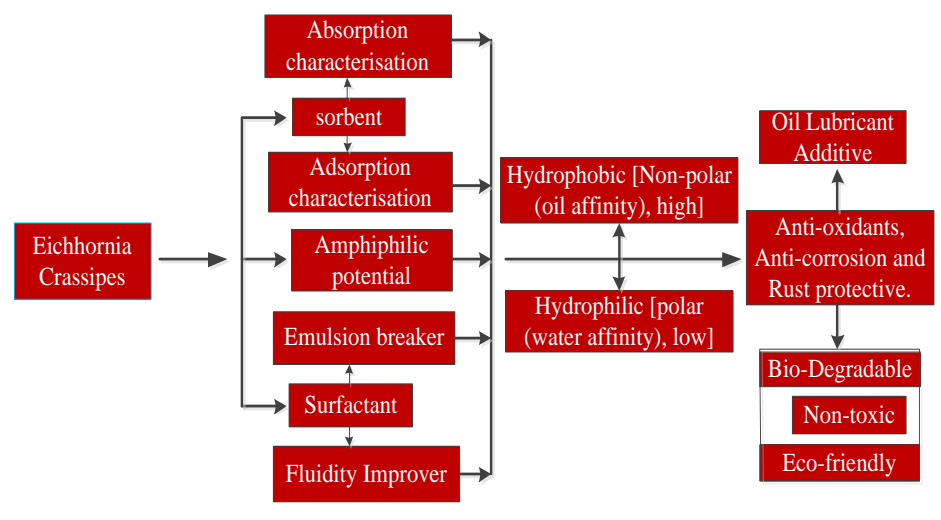

Figure 1. Eichhornia crassipes potentials for anti-oxidants application in oil samples

Eichhornia crassipes with good properties in super-hydrophobic and superoliephilic potentials was carried out with additional support of silica nanoparticles for pure homogeneous mixture. With the optimum mechanical and physiochemical properties of water hyacinth indicates it as one of the best bio-sorbent material in oil treatment processes and also anti-oxidant in performance [28]. All these properties are of paramount essentialities of Eichhornia crassipes in this study.lipids also called phospholipids as found in Eichhornia crassipes, are major components of the plasma membrane of water hyacinth and similar to triglycerides with slightly in structure and function [32]. The phospholipids are more in formation of lipid layers, that help in keeping the cell membrane structure [33], as described in figure 2 and 3 below. They are more rigid chemical structure than triglycerides in terms of oxidation stability. In the area of triglycerides, have glycerol and three fatty acids, that makes them fats. Function in maintaining the structure as phospholipids does. Also in resisting contaminants in the structure.

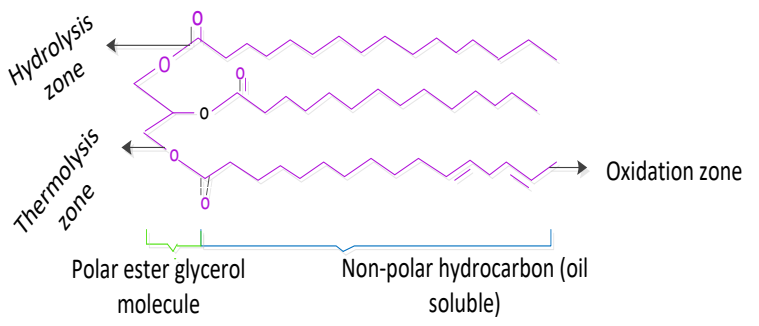

Figure 2: Triglyceride structure of lipid as found in water hyacinth indicating components in chemical reaction [12], [34].

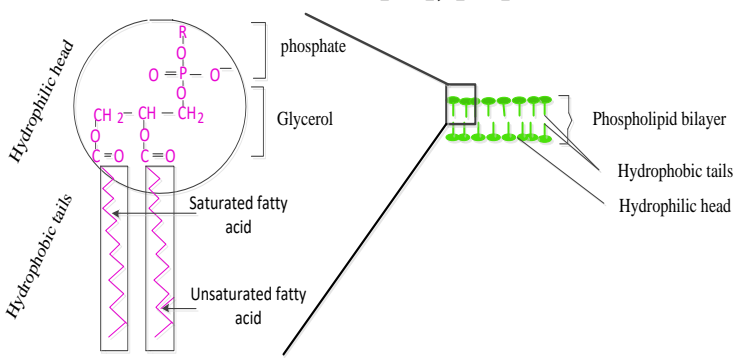

Figure 3: Phospholipid structure of hydrophobic and hydrophilic [33].

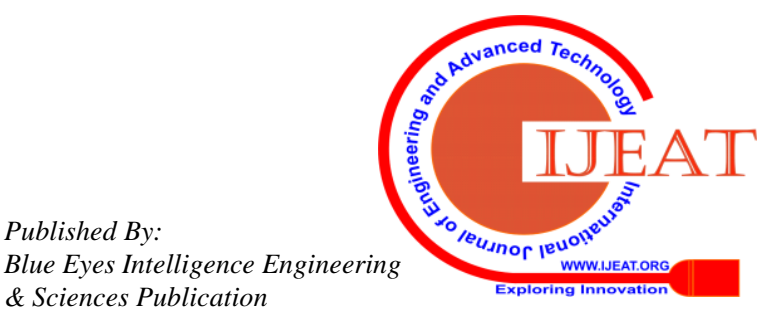


A phospholipid is classified as amphipathic molecule of both hydrophobic and hydrophilic parts of different percentages. The tail is made up of non-polar hydrophobic (oil affinity) constituents of fatty acid chains that repels water molecules, while the head is off polar hydrophilic (water affinity) constituents of phosphate-containing group. The membrane of phospholipids is arranged in a structural form called bilayer [32]. In the structure, the hydrophilic phosphate heads attached to the polar materials, whereas the hydrophobic lipids found soluble in the non-polar lubricant as illustrated in figure 3. This arrangement makes it possible for the anti-oxidation performance of prepared water hyacinth in oil sample [33]. If little of phospholipids is placed in an oxidative agent (water and contaminants), it spontaneously forms micelle of sphere-shaped structure. Usually discovered with hydrophobic non-polar faced inside based on the Van der Waals forces of attraction in the oil molecules and hydrophilic polar phosphate heads, attracted outside by the polar materials [35].

\section{OXIDATION PHASES OF OIL LUBRICANT IN SERVICE}

Lubricant, which consist of hydrocarbon base oil and additives, is subjected to various catalysts with conditions that permits initiation of oxidation to propagate. With these catalysts against base oil and additives, oxidation process sets in and certainly witness degradation. At the initiation phase, hydrocarbon molecules react with developed catalysts, forming some free radical and the reaction continue until perhaps averted by anti-oxidants or lead to complete lubricant degradation as show in figure 4.

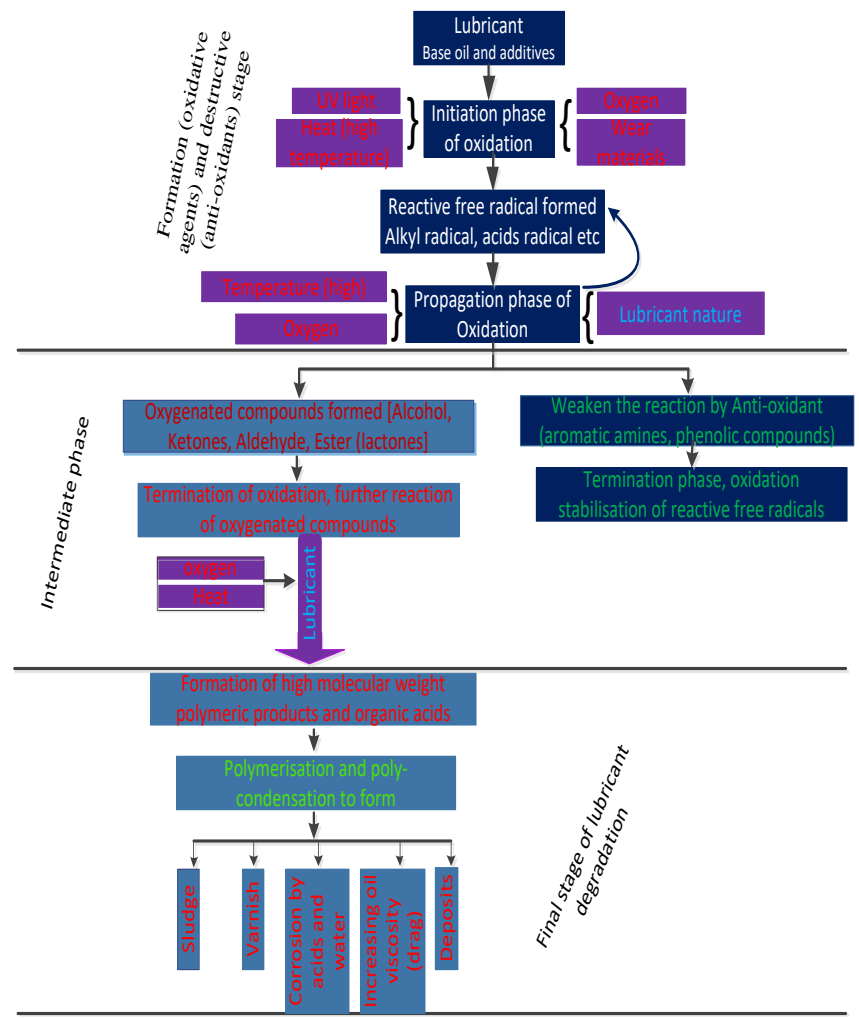

Figure 4. Illustration of oxidation phases in oil lubricant to the final degradation [36].

ree radicals been unwanted constituents in the system and promote oxidation. Highly reactive molecular fragments with one or more unpaired electrons, more prone to reaction with hydrocarbons and other molecules (hydro-peroxide, alkylperoxy, alkyloxy, hydroxyl etc). propagation continue with these free radicals and further generate oxygenated compounds. Oxidation is a chemical reaction [36], naturally develop between oil sample and oxygen from the surrounding and found to be primary oil degradation mechanism as shown in figure 5 .

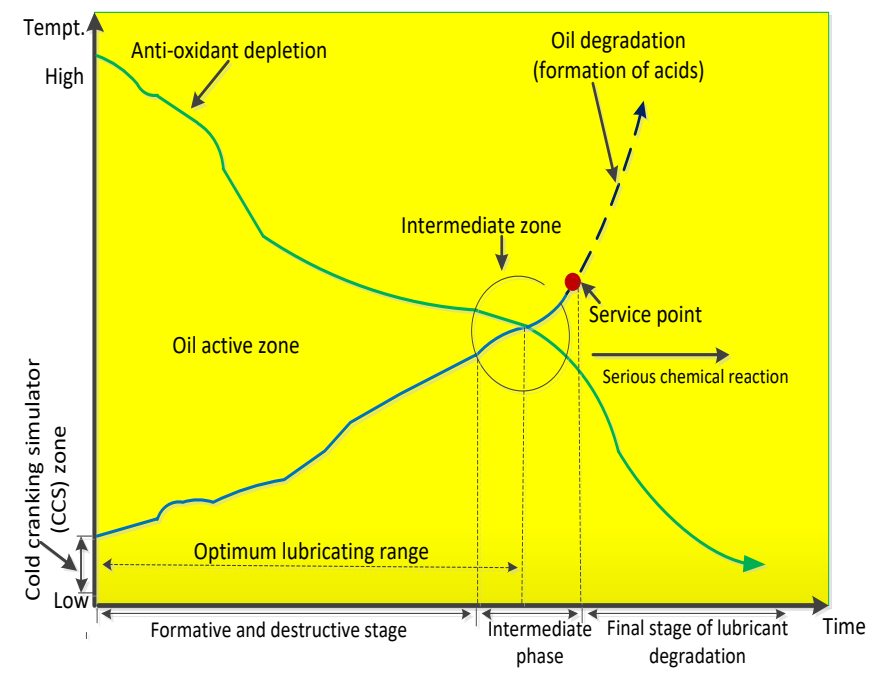

Figure 5. Effect of antioxidant depletion on oil lubricant life.

The process continues as temperatures increase, acids levels increase, active performance of additive decrease (anti-oxidants) [36], and accumulation of fine metal catalysts in the lubricating fluid (oil) is observed. There is an internal promotion of corrosion, pitting, wear, and rust impacts on the metal material surfaces as a result of inability of the lubricant and additives to perform its function.

\section{OXIDATION/CORROSION MECHANISMS IN HYDROCARBON MOLECULES (OIL SAMPLES)}

\section{(A). MECHANISM BY ELECTRON TRANSFER}

Protection of oil sample from attack of oxidation agents is done using anti-oxidants materials. Since oxygen is in abundant and by nature undergoes some reactions with many inorganic elements or compounds (metals, alkaline metal, alkaline earth metal and others) [37]. During cathodic transfer reaction, electron uptake from oxygen reactive metal surfaces as in figure 6 , leading to the formation of activated oxygen specie. The reaction products keep attacking hydrocarbon molecules by abstraction of hydrogen, producing peroxides and carbon radicals. The formed radical of carbon reacts to stabilize through abstraction of hydrogen leaving an alkene as new product. 


\section{Anti-Oxidant Property Of Eichhornia Crassipes In Oil Samples}
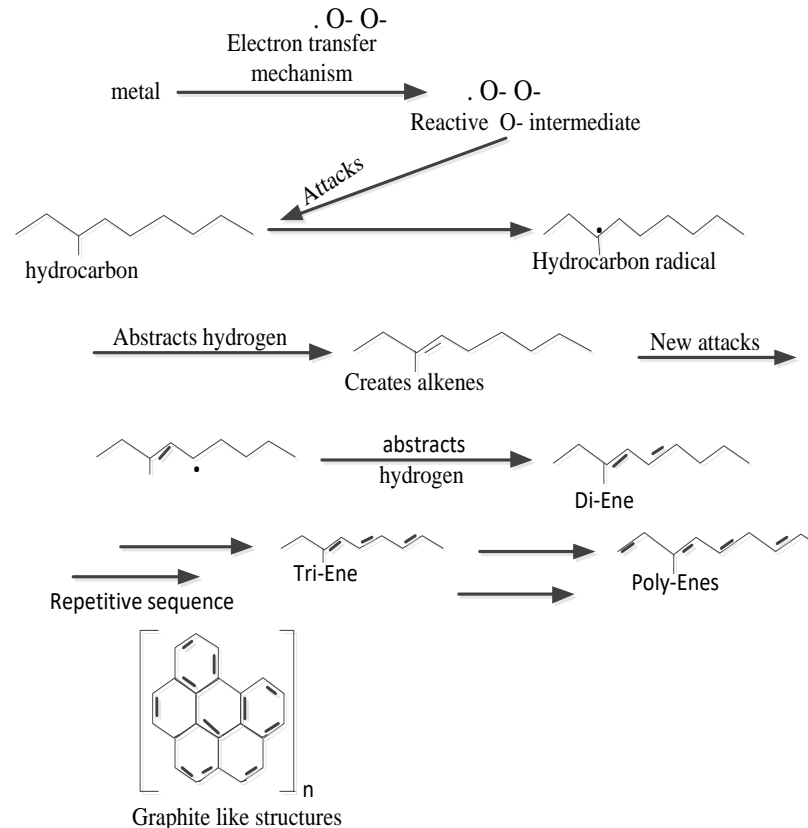

Figure 6. Oxidation mechanisms in hydrocarbon molecules by cathodic reaction [38].

The radical stabilization, with the formulation of alkene products which continue the oxidation process through removal stages of hydrogen. The further yield from that were di-tri, poly-alkenes and benzene rings as illustrated in the figure 3. At this stage of development and reaction in the oil lubricants, the quality of performance together with the tribo-characteristics has been degraded beyond the required.

\section{(B). MECHANISM BY ACTIVATED OXYGEN}

Another phenomena of oxidation apart from hydrogen elimination, is also by attacking carbon radicals by oxygen and other oxidants agents. This chemical reaction processes, produces acidic products that is the weakest constituents in oil mixture, illustrated in figure 7.

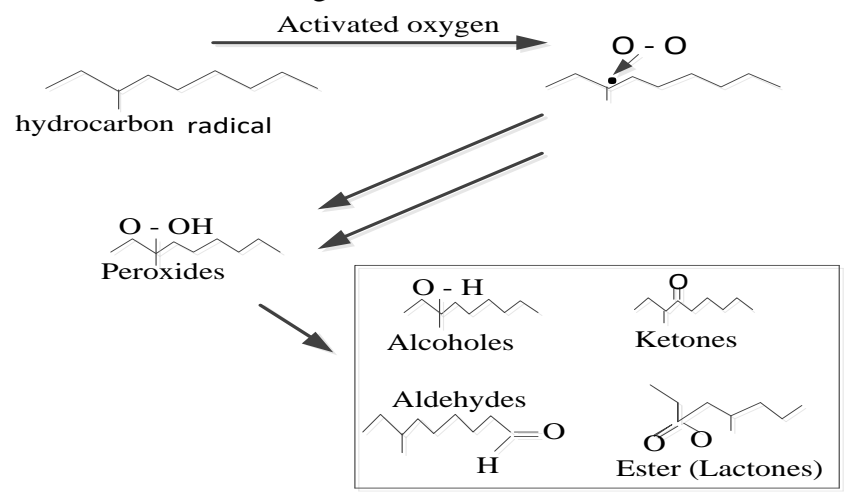

Figure 7. Base oil hydrogen elimination mechanism by activated oxygen [36].

Further reaction of oxygen with assisting oxygenated compounds results in formation of ester (lactones), carboxylic acid and water [36]. At severe temperature, the reaction increases with large of carboxylic acid and others. This persist together with great abstraction of hydrogen from the hydrocarbon molecules. The least formed products from the reaction include alcohols, aldehydes, carboxylic acids, ketones, and esters (lactones) which are compounds of carbonyl group. Formation of insoluble products, organic acids and water, which corrosively attack base oil. Lubricant viscosity increased (drag) as a result of condensation of ketones and aldehyde in the system [36]. The descried effects on the final product of system oxidation from the poly-condensation and polymerisation of the oxygenated compounds. The molecular compounds weight increase turns to form varnish, sludge and deposits.

\section{(C). CATALYTIC MECHANISMS}

The group of catalyst for the oxidation of organic compounds are carboxylates of metals shown in figure 8. For good solubility in the organic solvent (oil), these catalysts are highly lipophilic [35].

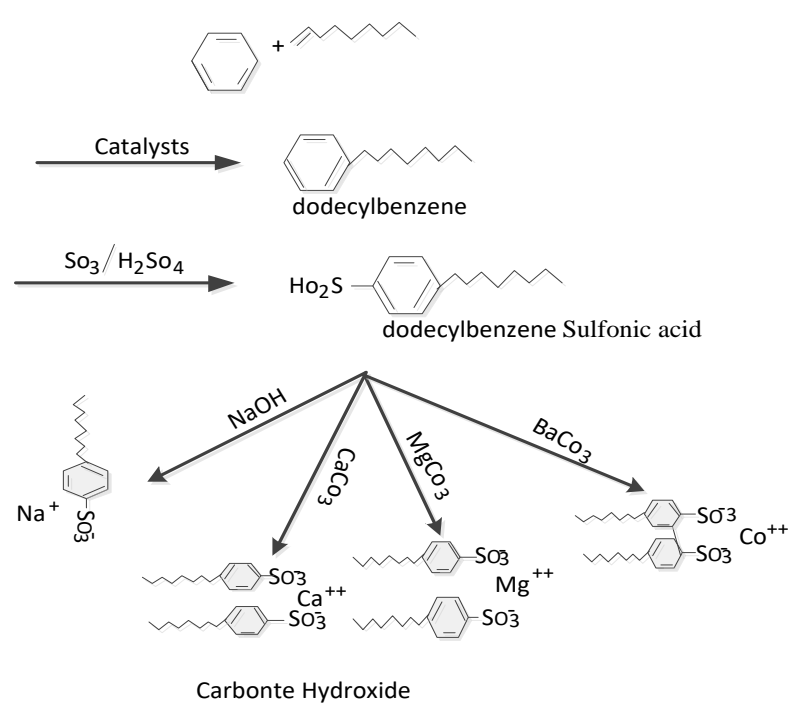

Figure 8. Base oil degradation by catalytic mechanisms[36].

Consequently, they also initiate radical chain reactions (auto-oxidation), forms organic radicals that further combine with oxygen to yield hydroxide intermediates in the process. All these occurrences are strongly supported by the bound energies that exist in the system.

\section{ANTI-OXIDANTS CLASSIFICATIONS OF EICHHORNIA CRASSIPES}

Antioxidants of natural form are the compounds that are present in mineral oil originally. They could be sulphur and nitrogen heterocyclics and polycycloaromatics or found in bio-oil as in triglycerides known as lutein, lycopene, zeaxanthin, astaxanthin etc [30]. However, the lack of these compounds during processing stages, makes it necessary to compensate and activate the lubricant with appropriate groups of additives. Generally, the available three types of antioxidants in eichhornia crassipes, include; radical scavengers (primary antioxidants), peroxide decomposers (secondary antioxidants) and metal passivators/deactivators [39]. Radical scavengers as found in phenolic, aromatic amines and also in sulfuret and phosphorus compounds which due stop oxidation chain propagation by blocking free radicals, generated in the initiation stage of the reaction. This scavenger's phenomena occur via donation of hydrogen atoms that react with alkyl radicals, with formation of quinones [32], [39]. 
Peroxide decomposers. Products of Eichhornia crassipes are organic in nature, contain little of organic sulphur (dialkylsulfides) and organic-phosphorus (triaryl phosphites) compounds with good potential of hydrogen-peroxides to non-radical derivatives like alcohols [40]. Metal deactivators of $\mathrm{N}$-salicylide ethylamine and benzotriazle, works as surface film-forming compounds of chelating agent (stable complex forming agents) with potential of reducing catalytic effect of metal ions on oxidation. Eichhornia crassipes is characterized by high potential of phytoremediation with chelating agent capable of pulling metal ions in their structure in form of stable complexes to repel the catalytic oxidation reaction of the metal ions [30], [40]. The mechanisms of film forming agents, covers the metal surfaces thereby prevents the particles in contacting with the oil phase.

\section{THE CHEMISTRY OPERATION OF ANTI-OXIDANTS IN OIL SAMPLES}

The mechanism involves the action of active antioxidants against oxidation agents. Two main principle mechanisms were proposed for antioxidants in service. It started with chain-breaking mechanism which is the first stage. This is done by electrons donate by the primary antioxidants to the free radicals (lipid) [38], present in the lubricant (oil sample). Second stage comes with mechanism of removal of reactive oxygen species (ROS) and reactive nitrogen species (RNS) as the initiator by preventing the continuation of the reaction by chain initiator catalyst as in figure 9 .

\begin{tabular}{|c|c|c|c|c|}
\hline $\begin{array}{l}\text { In'tiation stage } \\
\text { (1) } \mathrm{RH}^{\prime} \mathrm{R}^{\prime}+\mathrm{H}^{\prime} \\
\text { (2) } \mathrm{R}^{\prime} \mathrm{R}^{\prime}+\mathrm{O}_{2} \mathrm{ROO} \\
\text { (3) } 2 \mathrm{ROOH} \mathrm{ROO}^{\prime}+\mathrm{RO}^{\prime}+\mathrm{H}_{2} \mathrm{O}\end{array}$ & $\rightarrow$ & $\begin{array}{l}\text { Propagation stage } \\
\text { (1) } R^{\prime}+O_{2} R O O^{\circ} \\
\text { (2) } R_{0} 0^{\circ}+R H R O O H+R^{\prime} \\
\text { (3) } R O^{\prime}+R H R O H+R^{\prime}\end{array}$ & $\rightarrow$ & $\begin{array}{l}\text { Termination stage } \\
\text { (1) } R^{\prime}+R^{\prime} R-R \\
\text { (2) } R^{\prime}+R O O^{\prime} R O O R \\
\text { (3) } R O O^{\prime}+R O O^{\prime} R O O R+O_{2}\end{array}$ \\
\hline
\end{tabular}

Figure 9. Sequence of antioxidant reaction in oil lubricant [41].

Antioxidants $+\mathrm{O}_{2}$ oxidized antioxidants, in free radical chain reaction, facts in contact with oxygen to form unsaturated fatty acids which give rise to free radicals thus affecting the hydrogen element in the lubricant. The antioxidants added to it, neutralizes the free radicals by donating one of their own electrons ending the reactions [40]. Termination through breaking the reaction and render the propagation inactive. Chain breaking anti-oxidants with high hydrophobicity, surfactant and sorbent. Such potential as well as aromatic amines or phenolic, react with the free radicals (oxidation agent) to form inert or weak by-products and stable radicals.

\section{THE SCAVENGER OPERATION OF LIPID COMPOUNDS OF EICHHORNIA CRASSIPES IN OIL LUBRICANT}

Lipids (phenolics) as free radical scavengers and metal chelator or chitins [41]. Phenolic compounds ( $\mathrm{POH}$ ) of lipids acts as free radical acceptors and oxidation chain breakers. They interfere with oxidation process and other molecules by rapid donation of a hydrogen atom to radicals (R) as in equation 1.

$$
\mathrm{R}+\mathrm{POH} \rightarrow \mathrm{RH}+\mathrm{PO}^{\prime}
$$

Phenoxy radical (PO) formed are relatively stable due to it resonance tendency, thus make it so difficult for new oxidation chain reaction to develop or initiated. Also function as terminators of propagation sequence of reacting with other radicals, illustrated in equation 2 .

$$
\mathrm{PO}^{\circ}+\mathrm{R} \rightarrow \mathrm{POR}
$$

Lipids compounds of water hyacinth possess potential chemistry structure for free radical scavenging function, owing to the following.

- Phenolic hydroxyl group contain free electron radical and has good tendency of donating hydrogen atom [41]

- Delocalize an unpaired electron through projected conjugated aromatic system.

In the area of metallic ions, phenolic compounds with gallate and catecholate groups can inhibit metal-induced oxygen radical formation either by coordination with $\mathrm{Fe}^{2+}$ and enhancing autoxidation of $\mathrm{Fe}^{2+}$ as shown in equation 4 below, or serious development of inactive complex with $\mathrm{Cu}^{2+}, \mathrm{Fe}^{2+}$, or $\mathrm{Cu}^{+}$with slow and weaker interaction [35]

$$
\mathrm{H}_{2} \mathrm{O}_{2}+\mathrm{Cu}^{+} \text {or Fe } e^{2+} \rightarrow \mathrm{Cu}^{2+} \mathrm{OrFe}^{3+}+\mathrm{OH}+\cdot \mathrm{OH}^{-}
$$

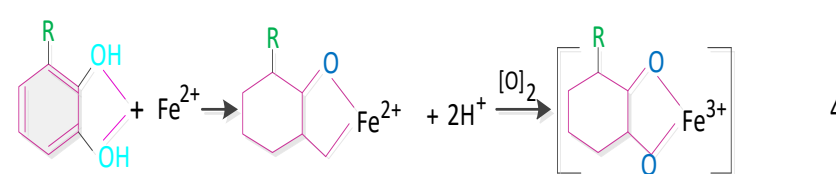

In practice, these two active antioxidant in equation 4 above, yields reduction of the steady state action and concentrations of free radicals and oxidant species. As a result, target of oxidation molecules on antioxidants such as lipids (phenolic acid), ascorbate and flavonoids is diminished [32]. Based on these potential capacities, antioxidant activities of natural phenolics as can formulated from water hyacinth should be successfully utilized in oil lubricants.

\section{CONCLUSION}

The function and properties of oil lubricant in our industrial machines gets diminished due to subjected activities. This unwanted situation developed, mostly based on lubricant inadequate oxidative stability. Modifications as to improve the oxidative property of oil samples with bio-materials are seriously yielding positive results. The achievement is based on the high hydrophobicity and the molecular structure of Eichhornia crassipes. The use of bio-antioxidants, well established as relatively effective and cheap of obtaining oxidative stability improvements. The good percentage of monounsaturated compounds with little of polyunsaturated constituents provides suitable oxidation stability and desired fluidity in the system. The performance of this antioxidants shows high resistance of oxidative agents and effectiveness in low percentage of toxicity and eco-friendly attributes. Eichhornia crassipes exhibited good synergies with other additives in the oil sample, resulting in optimum solubility in lubricants, also with great amphipathic molecule for good lubrication. The work was seriously investigated and proves natural organic antioxidant operation with good tribological behavior in service owing to the anti-oxidant potentials in the material used 


\section{Anti-Oxidant Property Of Eichhornia Crassipes In Oil Samples}

\section{ACKNOWLEDGEMENT}

The authors acknowledge the research grants provided by Universiti Tecknologi Malaysia, under GUP project no. Q. J130000.2524.20H29 and FRGS project no. R. J130000.7951.5F057 as well as IDF intervention code of 178-Biasiswazah Utm Idf.

\section{REFERENCES}

1 S. Rechard and R. Pearson, "Improving the performance of internal combustion engines through lubricant engineering Improving the performance of internal combustion engines through lubricant engineering," 2016.

2 M. Cai, Y. Liang, F. Zhou, and W. Liu, "A novel imidazolium salt with antioxidation and anticorrosion dual functionalities as the additive in poly(ethylene glycol) for steel/steel contacts," Wear, vol. 306, no. 1-2, pp. 197-208, 2012.

3 V. Gatto, "The Chemistry and Function of lubricant additives and their effectiveness depends on the bse oil and how they interact with other chemicals," Tribology Lubric Ation Technolog Y, Vol. 187, No. 1, 2011.

4 P. D. Srivyas and M. S. Charoo, "A review on tribological characterization of lubricants with nano additives for automotive applications," Tribol. Ind., vol. 40, no. 4, pp. 594-623, 2018.

5 H. Ghaednia and R. L. J. Advisor, "The Role of Nanoparticles in Lubricants ; Performing Lubricated and Dry Friction Tests," vol. 2019 , pp. 1-6, 2014.

6 R. K. Singh, O. P. Sharma, and A. K. Singh, "Evaluation of cellulose laurate esters for application as green biolubricant additives," Ind. Eng. Chem. Res., vol. 53, no. 25, pp. 10276-10284, 2014.

7 R. Rosentsveig et al., "Fullerene-like MoS 2 nanoparticles and their tribological behavior," Tribol. Lett., vol. 36, no. 2, pp. 175-182, 2009.

8 Opie oil Limited and TecAlliance oil Limited, "Engine, Gear Oil \& Grease Viscosity / Grade Classifications Explained We explain the mechanics behind the different grade classifications of car / motorcycle oils \& greases .," 2019, pp. 1-8.

9 V. W. Wong and S. C. Tung, "Overview of automotive engine friction and reduction trends-Effects of surface, material, and lubricant-additive technologies," Friction, vol. 4, no. 1, pp. 1-28, 2016.

10 P. Olander, "Tribology for Greener Combustion Engines," in Digital Comprehensive Summaries of Uppsala Dissertations from the Faculty of Science and Technology, 2018, p. 1607.

11 J. A. C. Da Silva, A. C. Habert, and D. M. G. Freire, "A potential biodegradable lubricant from castor biodiesel esters," Lubr. Sci., vol. 25, no. 1, pp. 53-61, 2013.

12 W. Liew Yun Hsien, "Utilization of Vegetable Oil as Bio-lubricant and Additive," pp. 7-17, 2014.

13 J. Salimon, N. Salih, and E. Yousif, "Improvement of pour point and oxidative stability of synthetic ester basestocks for biolubricant applications," Arab. J. Chem., vol. 5, no. 2, pp. 193-200, 2012.

14 P. U. Aldana, B. Vacher, T. Le Mogne, M. Belin, B. Thiebaut, and F. Dassenoy, "Action mechanism of WS2 nanoparticles with ZDDP additive in boundary lubrication regime," Tribol. Lett., vol. 56, no. 2, pp. 249-258, 2014.

15 S. Brown, "Base Oil Groups: Manufacture, Properties, and Performance," Tribol. Lubr. Technol., no. April, pp. 32-35, 2015.

16 S. Giovanni, "Lubricants and their composition," Tribology Series. pp. 59-119, 1993.

17 G. Gorla, S. M. Kour, K. V. Padmaja, M. S. L. Karuna, and R. B. N. Prasad, "Preparation and properties of lubricant base stocks from epoxidized karanja oil and its alkyl esters," Ind. Eng. Chem. Res., vol. 52, no. 47, pp. 16598-16605, 2013.

18 C.-H. Kuo, Tribology-Lubricants and Lubrication. In Tech. 2011.

19 L. R. Rudnick, "Synthetics, Mineral Oils, and Bio-Based Lubricants: Chemistry and Technology, Second Edition," pp. 1-2, 2019.

20 Y. Wang, "The study advance on effects of molecular structure of group II, III and III base oils on oxidation stability. Lubricating oil.," Chem. Technol. Lubr., pp. 1-41, 2012.

21 A. Tripathi and R. Vinu, "Characterization of Thermal Stability of Synthetic and Semi-Synthetic Engine Oils," Lubricants, vol. 3, no. 1, pp. 54-79, 2015.

22 J. C. Erny, M. P. Ospisil, and G. S. Ebor, "Composition and Oxidation Stabilityof Sae 5W-40 Engine Oils,” Tribol. Int., vol. 34, pp. 127-134, 2001.

23 N. Canter, "Use of antioxidants in automotive lubricants," Tribol. Lubr.
Technol., no. September, pp. 12-19, 2008.

24 A. Malik, "Environmental challenge vis a vis opportunity," Case Water Hyacinth, vol. 33, pp. 122-138, 2007.

25 E. Bernard, "Phytoremediation potentials of water Hyacinth. Eichhornia Crassipes (mart.) Solms in crude oil polluted water," J. Appl. Sci. Environ. Manag. Dec, vol. 17, no. 4, pp. 503-507, 2013.

26 M. Kumar, A. Afzal, and M. K. Ramis, "Investigation of physicochemical and tribological properties of TiO2 nano-lubricant oil of different concentrations," Tribol. - Finnish J. Tribol., vol. 35, no. 3, pp. 6-15, 2017.

27 Gulf Sea Grant, E. Maung-douglass, L. Graham, C. Hale, and S. Sempier, "Emerging Surfactants, Sorbents, and Additives for Use in Oil Spill Clean-Up."

28 Q. Zhu, Q. Pan, and F. Liu, "Facile Removal and Collection of Oils from Water Surfaces through Superhydrophobic and Superoleophilic Sponges," no. 3, pp. 3-7, 2019.

[29]M. J. Rani, M. Murugan, P. Subramaniam, and E. Subramanian, "A study on water hyacinth Eichhornia crassipes as oil sorbent," J. Appl. Nat. Sci., vol. 6, no. 1, pp. 134-138, 2018.

30 Q. Zhou et al., "The Effect of Various Antioxidants on the Degradation of $\mathrm{O} / \mathrm{W}$ Microemulsions Containing Esterified Astaxanthins from Haematococcus pluvialis," J. Oleo Sci., vol. 64, no. 5, pp. 515-525, 2015.

31 C. Rodkong, P. Sawngwong, and C. Issro, "A study on Efficiency of Natural Fiber Sorbent prepared from Water Hyacinth for Oil Sorption," vol. 10, no. 10, pp. 56-60, 2016.

32 N. Etsuo, Niki, Yoshiro, Saito, Yoshida, Yasukazu, "Lipid peroxidation: Mechanisms, inhibition, and biological effects," Biochem. Biophys. Res. Commun., vol. 1, no. 338, pp. 668-676, 2005.

33 M. Kashima, G. S. Cha, Y. Isoda, J. Hirano, and T. Miyazawa, "The antioxidant effects of phospholipids on perilla oil," J. Am. Oil Chem. Soc., vol. 68, no. 2, pp. 119-122, 1991.

34 J. Bart, E. Gucciardi, and S. Cavallaro, "Principles of lubrication," Biolubricants, pp. 10-23, 2012.

35 E. S. Budilarto and A. Kamal-Eldin, The supramolecular chemistry of lipid oxidation and antioxidation in bulk oils, vol. 117, no. 8. 2015.

36 F. Metrics, “Oil Degradation Mechanisms,” pp. 1-2, 2012.

37 W. Cai, meirong, Liang, Yongmin, Zhou, Feng and Liu, "supramolecular assembly of a novel low weight gelator Advanced molecular," J. Mater. Chem., vol. 21, no. 35, pp. 13399-13405, 2011.

38 D. A. Pratt, K. A. Tallman, and N. A. Porter, "Free radical oxidation of polyunsaturated lipids: New mechanistic insights and the development of peroxyl radical clocks," Acc. Chem. Res., vol. 44, no. 6, pp. 458-467, 2011.

39 Z.-H. Chen, Y. Saito, Y. Yoshida, and E. Niki, "Effect of Oxygen Concentration on Free Radical-Induced Cytotoxicity," Biosci. Biotechnol. Biochem., vol. 72, no. 6, pp. 1491-1497, 2008.

40 D. Johnson and J. Hils, "Phosphate Esters, Thiophosphate Esters and Metal Thiophosphates as Lubricant Additives," Lubricants, vol. 1, no. 4, pp. 132-148, 2013.

41 E. Kowalewska and G. Litwinienko, "[Phenolic chain-breaking antioxidants--their activity and mechanisms of action].," Postepy Biochem., vol. 56, no. 3, pp. 274-283, 2010.

\section{AUTHORS PROFILE}

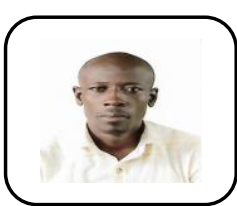

\section{Anthonyopia17@yahoo.com.}

MAILING ADDRESS. No 2 oloibiri street, D line, Port harcourt, Rivers State, Nigeria.

Phone No: +2347038272562

Phone No: +601160545940

Opia, Anthony Chukwunonso, is a citizen of Nigeria, born in 1984. He had his bachelor degree in Marine Engineering of Niger-Delta University Nigeria (2008). Also obtained Master's degree in Mechanical Engineering (thermo-fluid) from University of Port Harcourt, Nigeria (2017). During these period of time, He works with many Engineering Establishments include: Consolidated construction company (CCC), Frama Marine and Mechanical Services Company, Faraday Heavy Equipment Services Company, all in Nigeria. Thereafter, Established and became giant in Automobile Spar parts distribution with name Opiasco International Nigeria. Currently, pursuing his $\mathrm{PhD}$ in Mechanical Engineering, (TRIBOLOGY) in Universiti Tecknologi Malaysia (UTM). He has good skill in Engine maintenance both theoretical and practical. 
He is member in Maritime industry (STCW 95) certificate of Mandatory's Nigeria (Fire Prevention and Personal Survival Techniques, Elementary First Aid, Personal Safety and Social Responsibilities) International Civil Aviation Organization Training Directory (Airside and Landside), General Health, Safety and environment (HSE level 1,2 and 3).

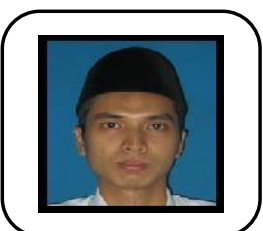

Office Tel. No.: 07- 5534667

Mobile Tel. No.: 016-4476219

Fax No: 07-5566159

E-mail : kameil@mail.fkm.utm.my

Dr. Mohd Kameil bin Abdul Hamid, is a citizen of Malaysia, born in 1977 in Malaysia. He is married. A senior lecturer(DS52) and lectured in the department of Automotive, in faculty of Engineering and also training officer, Automotive UG Programme Coordinator, Industrial Training Supervisor for Faculty of Mechanical Engineering, Committee Member of Faculty of Mechanical Engineering Annual Report, Committee Member of FKM Final Year Project. He attended his first section of education in Sijil Pelajaran Malaysia,Royal Military College, Sungai Besi, Kuala Lumpur (1994). Proceeded for Certificate of Associate American Degree Program, Preparatory Centre (PPP-ITM), Shah Alam, Selangor (1998). Thereafter attended and got B.Sc. in Mechanical Engineering, State University of New York, Buffalo, USA (2000). He obtained his Master's in Automotive Engineering, University of Leeds, UK (2003). His PhD was in Automotive Tribology, The University of Western Australia, Perth, Australia (2011). He had many professional affiliations such as; Graduate Member of Board of Engineers Malaysia (68702A) (April 2011), Life Member of Malaysia Tribology Society (L0613). He is a project consultant with Proton-UTM Brake Squeal Project (2010-2013), Malaysian Driving Cycle Project, Malaysia Automotive Institute - UTM. (2017-2018), He has published over twenty-six journals and also presented over nineteen international and national conferences. In view of his profession, training and courses attended include; Effective Communication using Social Network, Computer Lab, CTL UTM, 27 May 2015, CDIO Learning Innovation Workshop, CTL FKM UTM, 26-27 Aug. 2014, Assessment \& CQI Course, Seminar Room, FKM UTM, 15 May 2014, Open Courseware (OCW) Workshop, Ancasa Resort All Suites, Port Dickson, 8-10 March 2013, EAC Assesment workshop, Marriot Hotel, 26 May 2013, Bengkel Pemurnian Kertas Kerja Kejuruteraan Sarjana (Automotif), UTM, 12 Sept. 2013, SAR Report workshop, UTM, 18 Sept. 2013.

Research interest: Automotive Tribology, Friction Material, Lubrication oil. Focusing on friction and wear control in braking system under normal and contaminant environment. Investigating third body, external particle size and shape effect on the friction, wear and noise of the automotive friction material. Also studying the oil palm as bio-oil lubricant for automotive application.

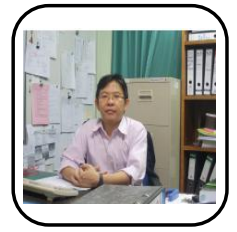

Telephone: +607-553-4699

Headphone: +6019-789-8975

Fax: +607-556-6159

Email : syahruls@mail.fkm.utm.my

Web : http://www.fkm.utm.my/ syahruls/

Prof. Syahrullail Samion is a senior lecturer and Director in the Faculty of Mechanical Engineering, Universiti Teknologi Malaysia, 81310 UTM, Skudai, Johor, Malaysia. He is from Malaysia. Obtained his PhD from Kagoshima University, Japan (2004) in the field of Tribology. His Master's was at Kagoshima University, Japan (2000) and also Bachelor's in the same institution Japan (1996). He supervises graduate/undergraduate students, lectures many courses in the institution with other Expertise experiences include; Tribology in Metal Forming, Friction and wear test (Tribotester), Bio-lubricant, Palm Oil as Lubricant, Fluid Mechanics. He has published over eighty journals with numerous conferences. He also has written many text books of high impact in the Engineering discipline.

PROFESSIONAL

MEMBERSHIP

Registered with Board of Engineers Malaysia (BEM)

Member of The Institution of Engineers Malaysia (IEM)

Member of Japanese Society of Tribologist (JAST)

Member of The Japanese Society for Technology of Plasticity (JSTP)

Member of Japan Institute of Light Metal (JILM)

Member of My Tribos

AWARDS

Distinction Service Award, Universiti Teknologi Malaysia, 2006
Distinction Service Award, Universiti Teknologi Malaysia, 2009 Best Paper Award (Bronze) in ASEAN Conference on Scientific and Social Science Research (ACSSSR 2011)

Outstanding Paper Awards in The 4th International Meeting on Advances in Thermofluids (IMAT 2011)

\section{PROFESSIONAL}

SERVICES

University

Committeemember of FKM promotion

Committee member for the 4th Asian International Conference of Fluid

Machinery (AICFM2009)

Committee member for FKM 2009 annual report

Committee member for UTM Innovation \& Creativity Festival

Committee member for Konsortium Perisian Terbuka

Committee member of FKM colloquium

Committee member of UTM promotion group

Committee member for Jom Masuk U

Coordinator for course Mechanic of Fluids ( $I$ and II)

Coordinator for fluid mechanics laboratory

Coordinator for part-time master programme of FKM

Faculty supervisor for student practical training

Interviewer for Zamalah Scholarship UTM

$\begin{array}{llll}\text { Interviewer } & \text { for } & \text { Degree } & \text { program }\end{array}$

Moderator for SME1902

Moderator for bengkel kejuruteraan

Evaluator for UTM Research University Grant Scheme Examiner for viva in FKM, UTM Invited for speech in Majlis Cetusan Pemikiran, Majlis Professor UTM Member of the MoU with Kagoshima University, Japan. Leader of the MoU with Orec Ind Sdn Bhd Chief Editor for Special Edition on Latest Trend in Fluid Mechanics

\section{EXPLORATION}

National

External Examiner for Master (Research) from Universiti Kebangsaan Malaysia

External Examiner for Master (Research) from Universiti Sains Malaysia. Secretary for the 4th International Meeting on Advances in Thermofluids IMAT 2011

Editorial Board of Journal of Mechanical Engineering and Technology, UTEM.

\section{Internationa}

Reviewer for Scientia Iranica

Reviewer for Journal of Material Science and Engineering $C$ Reviewer of Engineering Science and Technology (JESTEC)

Reviewer for Journal of

\section{RESEARCH}

Research theme:

Conducting research in bio-lubricant, tribology in metal forming, micro-pitting, palm oil as lubricant, fluid flows. 